\title{
Development of public services in the energy field in the age of digital economy
}

\author{
Elena Voskresenskaya ${ }^{1,}$, Lybov Vorona-Slivinskaya ${ }^{2}$, and Lybov Achba $^{3}$ \\ ${ }^{1}$ Peter the Great St.Petersburg Polytechnic University, 195251, St. Petersburg, Polytechnicheskaya \\ str., 29, Russia \\ ${ }^{2}$ Saint Petersburg State University of Architecture and Civil Engineering, 190005, St. Petersburg, 2nd \\ Krasnoarmeyskaya str., 4, Russia \\ ${ }^{3}$ Financial University under the Government of the Russian Federation, St. Petersburg branch, \\ Sezzhinskaya str., 15-17, St. Petersburg, 197198, Russia
}

\begin{abstract}
The development of the system of electronic public services, which is one of the directions of change in the digital economy, was the subject of the study in the present article. This system helps the state to interact with the population and organizations in such issues as providing information, particularly on individual requests, organizing public (municipal) procurements, in the matter of prices and tariffs in the energy sector, in providing public services and developing the feedback system (complaints institution), etc. The authors have concluded that a modern state should ensure the coherence between its citizens or business entities and institutions or public administrations on the basis of electronic access. Correct digitization of public administration contributes to the transparency of the public sector. Russia has enough prerequisites for the development of the electronic public services system, since Russia has traditionally established and maintained a high level of people's education, and these days, the information technology sector develops rapidly. The study identified the main features of information and communication technologies and determined the impact of these technologies on the formation of a system of socio-economic relations and the institutional environment of modern society. The authors substantiated the necessity of a new technology package in Russia that will ensure the transition from analog to digital control methods in the energy industry and support the transformation of consumer behavior models, business practices of energy supply and service companies.
\end{abstract}

\section{Introduction}

The rapid development of information and communication technologies (ICT), particularly the Internet, is one of the global processes of modern times that determine the transition to a new type of economy and society, which is called the digital (information) economy similarly with the concept of industrial economy. The digital economy has the following features: transferring of a significant part of social (including economic)

\footnotetext{
* Corresponding author: elenvoskr@mail.ru
} 
interactions to the Internet; development of remote forms of employment and information transfer; replacement of direct labor with robotized and programmable (digitalization of a significant part of production); the emergence of electronic money; globalization of the interaction of economic agents, including through the formation of global value networks (reducing the impact of geographic location factors); development of e-democracy (open data, e-voting, including open voting).

Therefore, the purpose of the study is to identify new socio-economic relations arising in the process of forming the information and communication space between the state and society, to elaborate a concept for the development of an electronic public services system, revealing the essence and specifics of this phenomenon.

Much attention in the scientific literature is paid to the study of the nature and characteristics of electronic services in such sectors of the economy as: e-commerce [1], ebanking services [2], educational services [3], consulting services [4], training, information services [5], e-government [6]. Some previous works of the authors of the present article are dedicated to the features of state and society interaction when transactions between the state, citizens and organizations are partly performed in the electronic form [7-15]. However, due to the complexity of the problem, there are still many theoretical and practical gaps in its studying. In particular, the economic and socio-political aspects of the functioning of the electronic public services have not been studied sufficiently.

\section{Materials and Methods}

The methodological basis of the study is the main provisions of modern economic theory, including institutional theory and political economy, the elaborations of leading Russian and foreign scientists in the field of computerization of public services.

Informational basis of the research was provided by legislative and regulatory acts of the Russian Federation, methodological and reference materials, statistical data of state bodies and scientific centers, reports and analytical studies of Polish, Russian and foreign scientists on the introduction of new information technologies, state standards of the federal and regional levels in the field of information, materials of federal target and state programs, proceedings of scientific and practical conferences, data from periodical literature, reports of information agencies, materials from official Internet sites.

\section{Results}

The study has substantiated that at the present stage of economic development, information and computer technologies increasingly influence not only technological, but also institutional environment of the society. ICT being widely applied change the structure of the economy, price proportions and the current configuration of power. Among others, ICT have modified the principal-agent problem: on the one hand, ICT reduce the problem of information asymmetry by converting most of the information into digital format and creating multiple search engines. On the other hand, due to the collection of data on behavior in the network, preferences of information consumers are revealed and ways of influencing their behavior are improved.

Based on the political-economic approach to ICT studying, the socio-economic content of the "the system of electronic public services" concept, which rests on the selection of various forms and types of e-government services, is revealed. Table 1 provides information on how people interact with public services [16]. 
Table 1. Methods of people interactions with public authorities in obtaining public services, in $\%$ of the total population aged $15-72$ years.

\begin{tabular}{|l|l|l|l|}
\hline \multicolumn{1}{|c|}{ Region } & $\mathbf{2 0 1 5}$ & $\mathbf{2 0 1 6}$ & $\mathbf{2 0 1 7}$ \\
\hline Interacted via, total & $\mathbf{4 6 . 4}$ & $\mathbf{5 6 . 1}$ & $\mathbf{6 5 . 7}$ \\
\hline Internet & 18.4 & 28.8 & 42.3 \\
\hline Personal visit & 21.2 & 22.5 & 24.0 \\
\hline Municipal center of public services & 7.1 & 11.8 & 18.9 \\
\hline Did not interact & 53.6 & 43.9 & 34.3 \\
\hline
\end{tabular}

Statistics show a steady increase in the number of entities accessing public services. It is substantiated that electronic services can be provided in two main forms: in the form of activities and in the form of access. Services in the form of activities include transformational and transactional services. The result of the first is the direct satisfaction of any need, the creation of a new good; the result of the second is the redistribution of rights and freedoms between economic agents. Services in the form of access are the provision of consumer access to other (basic) goods, primarily information. The classification of state electronic services developed by the authors allows showing their specificity in the view of social relations arising on their basis. Using modern ICT, the state largely removes restrictions on the rights of citizens, including their access to information, inherent in private ownership of resources. Table 2 provides statistics on people receiving public services via the Internet [16].

Table 2. Population receiving government services via the Internet in 2017 by constituent entities of the Russian Federation, in \% of the total population aged 15-72 years.

\begin{tabular}{|l|c|}
\hline \multicolumn{1}{|c|}{$\begin{array}{c}\text { Constituent entity of the } \\
\text { Russian Federation }\end{array}$} & \\
\hline National average & $\mathbf{4 2 . 3}$ \\
\hline Chukotka Autonomous district & 8.8 \\
\hline Magadan region & 14.5 \\
\hline Oryol region & 14.7 \\
\hline Jewish Autonomous region & 15.2 \\
\hline Tyumen region & 64.5 \\
\hline Republic of Bashkortostan & 70.8 \\
\hline Republic of Tatarstan & 73.4 \\
\hline Moscow region Autonomous & 74.3 \\
\hline $\begin{array}{l}\text { Yamalo-Nenets } \\
\text { district }\end{array}$ & 83.2 \\
\hline
\end{tabular}

The table presents examples of the indicator from the minimum to the maximum with an average value for Russia of $42.3 \%$.

Based on a transactional approach to the study of the electronic public services system, the specific role of the state as a participant in transactions has been revealed. The study displayed that transactions involving the state can be both symmetrical and asymmetrical. Acting as a subject of private law, the state can participate in symmetrical (exchange) and asymmetrical (control) transactions. While acting as a subject of public law, the state participates only in asymmetric transactions (transactions of rationing and changing institutions). Unlike most studies, where the role of the state is reduced to the organization of transactions of rationing and changing institutions, the author considers the role of the state in such transactions as the exchange of rights and management. These functions are usually attributed only to private agents of the market. The demonstration of the fact that the state is actively involved in private relations, including provision of electronic services, leads to the conclusion of its complex role in socio-economic relations. Table 3 presents 
statistics on the receiving of public services by the population in electronic form, depending on the area type [16].

Table 3. Receiving of public services by the population in electronic form in urban and rural areas, in $\%$ of the total population aged $15-72$ years.

\begin{tabular}{|l|l|l|l|}
\hline \multicolumn{1}{|c|}{ Electronic service recipients } & $\mathbf{2 0 1 5}$ & $\mathbf{2 0 1 6}$ & $\mathbf{2 0 1 7}$ \\
\hline Total & & & \\
\hline Urban area & $\mathbf{3 9 . 6}$ & $\mathbf{5 1 . 3}$ & $\mathbf{6 4 . 3}$ \\
\hline Rural area & 43.9 & 55.7 & 67.7 \\
\hline
\end{tabular}

There is a gradual equalization of the indicator for the population of urban and rural areas.

Modern consumers are becoming increasingly demanding in terms of availability, reliability and quality of services, including in the energy sector. In this regard, it should be understood that it is difficult to significantly improve the efficiency of industry, which is based on traditional technologies, as well as meet new consumer demands without a noticeable increase in prices.

In Russia, the specifics of energy regulation are that each of the energy sectors is in a different economic state. This circumstance, as well as the presence of sectoral specifics, caused significant differences in their legal regulation. The reforms in the electric power field are of major interest. In 2003, the federal law "On Electric Power Industry" was adopted, aimed at market reforms in this sector. Shortly, a new legislation for the electric power field in Russia was created. The rules of the wholesale electricity market, approved by Decree of the Government of the Russian Federation No. 643 of October 24, 2003, set the pace for the gradual opening of the market to competition, according to which, since 2011, electricity is sold in full at free prices. Therefore, the management of the industry was decentralized, the replacement of vertical integration of management with horizontal one was designated, the main instrument of which is the commercial market infrastructure and a system of contracts.

Problems of protecting consumers of public services arise along with introducing of market mechanisms, which are accompanied by the privatization of production and sales, as well as open prices. Thus, these problems should be tackled by improving the institutional environment of the market that sets a fair price (competition, information transparency), introducing of model contracts that eliminate discriminatory conditions, giving freedom to choose the energy supplier through open discussions rather than by state-guaranteed price, as it was before.

\section{Discussion}

The new industrialization, that unfolds globally, will require a modern technological base (digital systems, additive and highly-precise production), which is often demanding to the reliability and the quality of the energy supply. So, this determines the emergence and development of "digital demand", share of which in a number of countries, according to some estimates, will be $20-30 \%$ by 2030 .

A significant increase in the efficiency of the entire power supply field of Russia can be achieved through a major introduction of the new technology package and its balanced implementation in the current energy sector. Technological modernization of traditional electric power industry should be also conducted. The main goal of the state policy in this field should be the formation of a scientific, technological and industrial basis for the implementation of an innovative (high-tech) scenario for the development of the power 
industry. At the same time, the main activities should be completed by 2022-2025, when, according to experts, a new investment cycle in the industry will begin.

In the technological agenda of Russia in the electric power industry for the medium term, the following priorities can be set:

- launch of open modular digital platforms for organizing cyber-physical systems and environments in the power industry;

- development of intelligent multi-agent control systems;

- the establishment of a market segment of electric energy storage systems (from batteries for electric vehicles and domestic household to high-capacity electric energy storage systems, including the technology for storing electricity in the hydrogen cycle);

- development of the advanced high-voltage and high-frequency power electronics;

- introduction of the "Internet of Things" (digital sensors, sensors, actuators and means of communication);

- use of digital financial technologies (blockchain, smart contracts, decentralized autonomous organizations).

An obstacle to the implementation of the strategic maneuver is that in the current institutional environment, the main market actors and infrastructure organizations are mostly not interested in the transition to the new technology package and to the new architecture. Whereas, retail consumers and subjects of distributed energy often remain outside the field of competitive mechanisms and face regulatory barriers to the implementation of new technological approaches to energy supply. In this regard, according to the authors of the report, the defining condition for the development of the new electric power industry in Russia should be a change in the architecture of the retail sector of the electricity market, deregulation of the economic relations of its subjects, creation of simplified interfaces for technological and information interaction of distributed energy with the Common Market (EEC), as well as introduction of mechanisms for distribution of system economic effect. These measures should result in the emergence of a new class of market subjects - active consumers and prosumers, operators of micro-energy systems and aggregators of distributed energy facilities, and various service organizations. This class of subjects will be interested in using new technologies and will create a demand for high-tech equipment and services. Consumers, in turn, will have the opportunity to choose energy supply options, which will stipulate the competition in the industry. In addition, special attention may also be paid to the intensification of the processes of creating, testing and introducing new technologies and practices in the industry. The result of the implementation of the strategic maneuver should be an increase in the attractiveness of the Russian electricity sector for investors.

\section{Conclusions}

The implementation of the innovative scenario in the electric power industry, according to experts of the working group of the National Technological Initiative in the field of energy ("Energynet"), will create prerequisites for holding the growth of electricity prices (it is predicted that electricity prices in 2035 may be reduced by $30-40 \%$ from the inertial scenario of electric power industry development) by increasing the efficiency of using generating and network capacities, significantly reducing the need for new capacities, reducing energy losses, reducing the cost of ownership of basic infrastructure. In addition, a scientific, technological and industrial potential will be formed for large-scale export of equipment, systems and services to global markets (the income of Russian companies may amount to about $\$ 40$ billion in 2035).

In Russia, despite the significant advancement of the new technological agenda in the energy sector (scientific projects, start-ups, the approval of the Forecast of the scientific and 
technological development of the fuel and energy complex of Russia for the period up to 2035, the adoption of the "Energynet" project plan of the National Technology Initiative) issues, that tied to the long-term priorities of the sectoral technology policy, as well as the optimal timing and mechanisms for the transition to a new energy system, still lie ahead.

\section{References}

1. L.S. Onokoy, A.V. Onokoy, Internet trading: problems and development perspectives 3, 35-38 (2015)

2. V.S. Aksenov, V.V. Obukhov, Electronic banking among banking services 4, 75-82 (2013)

3. E.N. Solovova, E-learning: current state of problem in higher education system of russia and foreign countries 6, 16-20 (2013)

4. M.V. Koptev, Assessment of the quality of public services in electronic form 5, 72-76 (2014)

5. Yu.V. Malakhova, E-business in the service industry 1, 214-219 (2014)

6. M. Pavlyutenkova, Russian electronic government: conceptual approaches and practice of realization 2, 90-104 (2013)

7. E. Voskresenskaya, V. Snetkov, A. Tebryaev, Z. Askarov, MATEC Web of Conferences 106, 08055 (2017)

8. E. Voskresenskaya, V. Snetkov, A. Tebryaev, E3S Web of Conferences 33, 03051 (2018) doi.org/10.1051/e3sconf/20183303051

9. E. Voskresenskaya, L. Vorona-Slivinskaya, E3S Web of Conferences 33, 03052 (2018) https://doi.org/10.1051/e3sconf/20183303052

10. E. Voskresenskaya, D. Mokhorov, A. Tebryaev, MATEC Web Of Conferences 170, 01058 (2018) DOI https://doi.org/10.1051/matecconf/201817001058

11. E. Voskresenskaya, N. Zhilskiy, E. Shariapova, MATEC Web Of Conferences 170, 01057 (2018) DOI https://doi.org/10.1051/matecconf/201817001057

12. P.K. Sun, L. Vorona-Slivinskaya, E. Voskresenskaya, IOP Conference Series: Earth and Environmental Science 90 (2017) https://doi.org/10.1088/1755-1315/90/1/012073

13. E. Voskresenskaya, L. Vorona-Slivinskaya, S. Panov, MATEC Web of Conferences 193, 02025 (2018) doi.org/10.1051/matecconf/201819302025

14. E. Voskresenskaya, L. Vorona-Slivinskaya, A. Loiko, Constitutional-legal issues of ensuring environmental safety in modern Russia 8(19), 57-59 (2018)

15. E. Voskresenskaya, L. Vorona-Slivinskaya, A. Loiko, Economic and legal problems devastated territories in the Russian Federation 7(18), 62-65 (2018)

16. Regiony Rossii, Sotsial'no-ekonomicheskie pokazatel (2017)

17. Russian Statistical Yearbook (2017) 